University of Nebraska - Lincoln

DigitalCommons@University of Nebraska - Lincoln

Faculty Publications, Department of Psychology

Psychology, Department of

3-9-1980

\title{
Female Sexual Arousal and the Menstrual Cycle
}

Paula Englander-Golden Ph.D.

paulaeg@sayitstraight.org

Horng-Shing Chang

Mary R. Witmer

Richard A. Dienstbier

University of Nebraska-Lincoln, rdienstbier2@unl.edu

Follow this and additional works at: https://digitalcommons.unl.edu/psychfacpub

Part of the Psychiatry and Psychology Commons

Englander-Golden, Paula Ph.D.; Chang, Horng-Shing; Witmer, Mary R.; and Dienstbier, Richard A., "Female Sexual Arousal and the Menstrual Cycle" (1980). Faculty Publications, Department of Psychology. 201. https://digitalcommons.unl.edu/psychfacpub/201

This Article is brought to you for free and open access by the Psychology, Department of at DigitalCommons@University of Nebraska - Lincoln. It has been accepted for inclusion in Faculty Publications, Department of Psychology by an authorized administrator of DigitalCommons@University of Nebraska - Lincoln. 
Published in Journal of Human Stress 6 (March 1980), pp. 42-48. Reprinted with permission of the Helen Dwight Reid Educational Foundation. Published by Heldref Publications, 1319 18th Street, NW, Washington, DC 20036-1802. Copyright C 1980.

\title{
Female Sexual Arousal and the Menstrual Cycle
}

\author{
Paula Englander-Golden, Ph.D., Horng-Shing Chang, Mary R. Whitmore, Ph.D., \\ and Richard A. Dienstbier, Ph.D.
}

\begin{abstract}
Self-reports of sexual arousal were significantly affected by conditions under which they were elicited. Such self-reports in women not taking oral contraceptives were congruent with a hormonal basis for such arousal only when the women were "unaware" that the study investigated sexual arousal as a function of the menstrual cycle. The "unaware" condition was operationalized by means of daily self-reports elicited from males and females for 11 weeks under the guise of a study of biological rhythms. A composite of one to three menstrual cycles for 26 women not taking oral contraceptives showed that sexual arousal during the luteal phase, when progesterone is relatively high, was significantly lower compared to peaks around ovulation. and premenstrual and late menstrual days $(\mathrm{p}<.02)$. For the "aware" condition. women were asked to remember moods for the premenstrual, menstruating and luteal phases of the very last cycle on which they had just finished giving "unaware" daily self-reports. A $2 \times 3$ analysis of variance (with "aware" versus "unaware" conditions and premenstrual, menstruating. and luteal phases of the last cycle as the two independent variables) yielded a significant interaction effect with $\mathrm{F}=6.5, \mathrm{df}=2,50, \mathrm{p}<.003$. In the "unaware" condition, sexual arousal was reported lowest during the luteal phase. The opposite pattern was reported in the "aware" condition. The results suggest that cyclical variability may not be simply due to women's misattributions. However, "awareness" has an effect on self-report measures and may bias reports according to cultural stereotypes. Daily self-reports of sexual arousal for men were averaged over the duration of the study. This average was 3.16. The equivalent average for women not taking oral contraceptives was 2.35 and for women taking oral contraceptives was 2.62. Analysis of variance of these three means yielded a significant difference with $\mathrm{F}=4.49 . \mathrm{df}=2,59, \mathrm{p}<.02$.
\end{abstract}

Reviewing the literature on the endocrinology of sexual behavior, Greenblatt et al. ${ }^{1}$ concluded that progestogens are related to a decrease and androgens to an increase in libido. On the other hand, administration of estrogens resulted in increased li-

Dr. Englander-Golden is Assistant Professor in the Department of Human Relations at the University of Oklahoma at Norman, where Ms. Chang is a graduate student in the Department of Psychology and Dr. Whitmore is As- bido only in some women, while others failed to respond. Since progesterone reaches peak levels during the luteal phase of a normal menstrual cycle, ${ }^{2}$ a hormonal view of female sexuality would predict a decrease in sexual arousal during the luteal phase

sistant Professor in the Department of Zoology. Dr. Dienstbier is Professor and Chairman of the Department of Psychology at the University of Nebraska at Lincoln. 
of ovulating women. Furthermore, even though daily testosterone levels are often at variance with each other, ${ }^{3}$ there is some evidence that testosterone shows a slight but significant increase around the time of ovulation. ${ }^{4}$ This peak in testosterone and the ovulatory peak in estrogens would be expected to predict heightened sexual arousal around the time of ovulation. Yet controversy persists regarding the location of self-reported highs and lows of female sexual arousal and activity as a function of the menstrual cycle. Highs and lows in sexual arousal have been found at different points in the menstrual cycle by different investigators. ${ }^{5-11}$ Some researchers have suggested that cultural or cognitive factors, rather than hormonal factors, are responsible for fluctuations in female sexual arousal, 8,12 and that any self-reported cyclical variability in moods may be due to women's misattributions. ${ }^{13}$ Finally, James ${ }^{7}$ suggested that there is little evidence for cyclical variability in female sexual arousal and some evidence that cyclicity in coital rates is determined "very largely" by the male.

The present study was designed to investigate the possibility that some of the above controversy could be due to the way self-reports have been elicited. Usually self-reports have been elicited with retrospective questionnaires on which women were asked to remember their moods as a function of the menstrual cycle. The use of such questionnaires has been criticized by Parlee ${ }^{14,15}$ because they make women "aware" that their moods and behaviors are being studied as a function of the menstrual cycle and can therefore be affected by cultural expectations about menstruation. Furthermore, Englander-Golden et al. ${ }^{16}$ have shown that retrospective questionnaires appear to measure stereotypic conceptions about menstrual cyclicity of certain moods and are not generally equivalent to daily self-reports elicited when women are "unaware" that the menstrual cycle is a salient part of the study. This is not to say that self-reports obtained from "unaware" women show no cyclical variability. Indeed Golub ${ }^{17}$ reported that "unaware" subjects showed more anxiety and depression during the premenstrual phase compared to the intermenstruum. Englander-Golden et al. ${ }^{16}$ also reported some cyclical variability in the "unaware" condition; however, they showed that retrospective questionnaires maximized the reporting of negative moods but minimized the reporting of positive moods for the premenstrual and menstruating phases.

In the present study, self-reports of sexual arousal were elicited by means of two types of question- naires. Daily self-reports were obtained under the guise of a study in biological rhythms. These daily reports represented the "unaware" condition. Data for the "aware" condition were obtained by asking women to remember their moods and behaviors during specific phases of their last menstrual cycle. It was hypothesized that women not taking oral contraceptives would give different self-reports of sexual arousal depending on whether they are aware or unaware that such arousal was being studied as a function of the menstrual cycle. Sexual arousal was predicted to follow patterns consistent with the hormonal view only in the "unaware" condition. That is, a decrease in arousal was predicted when progesterone levels are high and an increase when progesterone levels are low. Heightened sexual arousal was not predicted during menstruating days. Although progesterone levels are low during this phase, menstrual discomfort could be antagonistic to such arousal.

Cyclical variations in sexual arousal were not predicted in the "unaware" condition for women who were taking oral contraceptives. This prediction was based on results reported by Udry and Morris. ${ }^{6}$ These authors reported the disappearance of the luteal reduction in sexual activity for women taking oral contraceptives and attributed this effect to the lack of a luteal surge in endogenous progesterone due to the suppression of ovulation.

\section{METHOD}

\section{Subjects}

The study was conducted in an advanced undergraduate zoology class. Both men and women volunteered to participate in the study for additional credit. Of the 70 women in the class, 60 participated. Twenty-four of these were taking oral contraceptives. Data analysis was based on 26 nonpill women and 20 pill women. The rationale for subject selection is detailed in the Results section. Sixteen men also participated in the study.

\section{Procedure}

"Unaware" condition. The study was conducted for 11 weeks under the guise of an investigation of biological rhythms which might be common to both males and females. Male and female students were asked to fill out an 80-item daily mood questionnaire each evening. Items were rated on a sixpoint scale from "not at all" to "very." Factor anal- 
ysis indicated that sexual arousal was composed of the following items: sexy, lustful, passionate, and affectionate. The other items pertained to the larger scope of the study. ${ }^{16}$ Women were asked to make a note of onset and end of menstruation during the study so that such effects could be "factored out." This statement was strictly for cover purposes, since in reality these were precisely the effects under study. All subjects were asked to indicate any hormonal medication they might be taking during the study (such as insulin, thyroid, etc.). For women this included information about oral contraceptives.

"Aware" condition. Self-reports for the "aware" condition were elicited in the following manner: at the end of the study, the students were reminded that in order to analyze the data for biological rhythms common to both males and females, one has to eliminate or "factor out" effects due to menstruation. Women students were therefore asked to fill out the same questionnaire which they had been filling out daily, in terms of how long they remembered their most recent menstrual cycle. Specifically, they were asked to fill out the questionnaire in terms of average feelings during three phases of their last menstrual cycle. The premenstrual phase was defined for the subjects as the five days prior to the most recent menstruation, the menstruating phase as the days of most recent flow, and the luteal phase as days 13 through 7 prior to onset of most recent flow.

These time frames are somewhat arbitrary, but are based on hormonal data: progesterone is relatively high during days 13 through 7 prior to onset of menstruation, and low during the five premenstrual days. ${ }^{2}$ The actual occurrence of ovulation was not determined. Since anovulatory cycles are marked by the absence of progesterone, their possible inclusion in this analysis could only lower cyclical variability across the menstrual cycle.

At the end of the study, a postexperimental questionnaire was administered to determine any suspicions, and students were fully debriefed. Not a single student suspected the true nature of the study.

\section{RESULTS}

The analysis of data was restricted to 26 women not taking oral contraceptives and 20 women who were taking combination oral contraceptives. Women who were on insulin, on diet control medication, on sequential oral contraceptives or who did not have at least one complete menstrual cycle during the eleven weeks of the study were not included in the analysis. The progestin in the contraceptives ranged from $2.5 \mathrm{mg}$ to $0.3 \mathrm{mg}$; estrogen ranged from $100 \mathrm{mcg}$ to $30 \mathrm{mcg}$.

A composite picture of daily sexual arousal as a function of menstrual cycle days for women not taking and taking oral contraceptives is presented in Figure 1. Most women had more than one menstrual cycle during the 11 weeks of the study. Onset of menstruation was chosen as the reference point for locating specific days within each menstrual cycle and is indicated as day $\mathrm{M}$. The first four days following onset of menstruation are indicated as days 1 through 4 . The rest of the cycle was obtained by counting backwards from the onset; these reverse cycle days are indicated by negative numbers. Sexual arousal, reported on equivalent days of as many menstrual cycles as were incurred, was averaged for each woman before obtaining the composite for the particular group. The scores of sexual arousal reported during all the follicular days were pooled into one number ( $\mathrm{F}$ in Figure 1). This procedure was necessary because the menstrual cycles differed in length.

For women who were not taking oral contraceptives, Figure 1 indicates peak levels of sexual arousal on day -13 , which is close to ovulation, premenstrually (days $-2,-1$ ), and in the late menstrual day (day 4). The predicted low in sexual arousal spans days -11 through -3 . The average sexual arousal reported during these days was 2.21. This score is significantly lower than the average of the peak days $(-13,-2,-1,4)$, which was 2.43 ( $\mathrm{t}$ for correlated measures $=2.61$, $\mathrm{df}=25, p$ $<.02)$. Sexual arousal during the early menstrual days (M, 1, 2, 3,) was 2.16 and was also significantly lower than the average arousal reported during the rest of the menstrual cycle with the exception of the luteal days -11 through -3 ( $t$ for correlated measures $=2.51, \mathrm{df}=25, p<.02)$.

For women taking oral contraceptives, an unexpected minimum in sexual arousal was found during days -6 and -5 . The average score for these two days was 2.47 and was significantly lower than the 2.77 average obtained during the rest of the menstrual cycle, excluding early menstrual days $M, 1$, 2 , and 3 ( $\mathrm{t}$ for correlated measures $=2.28, \mathrm{df}=19$, $p<.05)$. This dip was not predicted, since oral contraceptives have been reported to erase cyclicity in sexual arousal by suppressing ovulation and thereby the luteal surge in endogenous progesterone. 


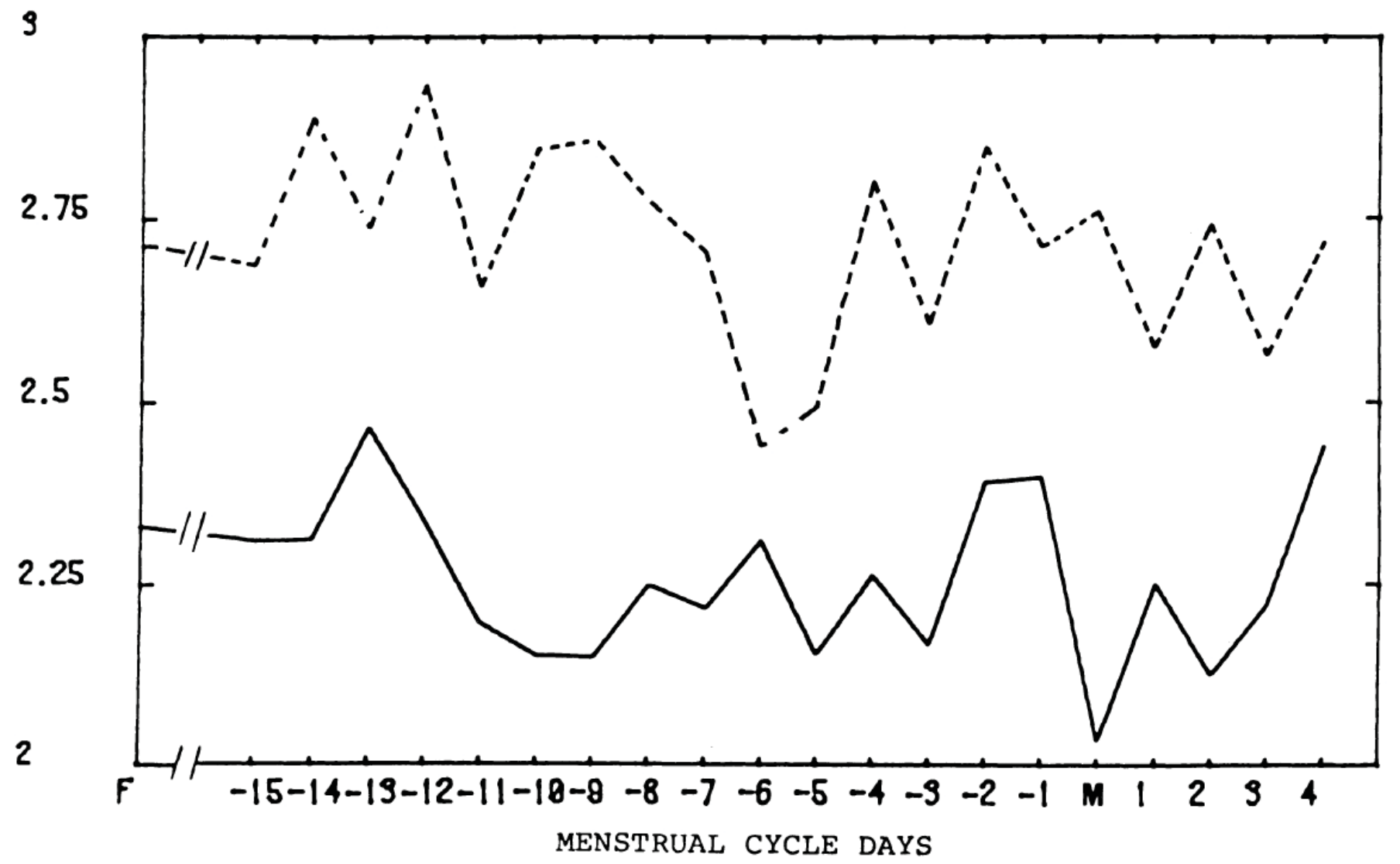

Fig. 1. Sexual arousal by menstrual cycle day. - Women not taking oral contraceptives. - - - - Women taking oral contraceptives. $\mathrm{M}=$ Onset of menstruation. $\mathrm{F}=$ Follicular phase.

To compare sexual arousal in the "unaware" and "aware" conditions, daily self-reports were pooled over the appropriate days of the last menstrual cycle to create the same premenstrual, menstruating, and luteal phases for which women had also given retrospective self-reports. Specifically, the 5 days prior to onset of last menstruation were pooled for the premenstrual phase, and days 13 through 7 prior to onset for the luteal phase. Since the number of days of flow vary, it was decided to pool the first 5 days after onset of last flow for the menstruating phase.

Table 1 shows the means of sexual arousal in the "unaware" and "aware" conditions reported by women not taking oral contraceptives. A $2 \times 3$ analysis of variance (with remembered versus daily self-reports and premenstrual, menstrual and luteal phases as the two independent variables) was performed on the above data. The results of this analysis are also included in Table 1.
The most interesting result in Table 1 is the interaction effect between type of questionnaire and menstrual cycle phase. As predicted, daily self-reports ("unaware" condition) show lowest sexual arousal during the luteal phase and are congruent with the hormonal hypothesis. The remembered questionnaire ("aware" condition), however, shows highest sexual arousal during this time and is in opposition to the hormonal hypothesis. The above interaction effect is significant with $\mathrm{F}=6.58, \mathrm{df}=$ $2,50, p<.003$.

Results in Table 1 also indicate that self-reports of remembered sexual arousal, averaged over the three phases of the menstrual cycle, were higher than those obtained from daily questionnaires. This difference barely missed the commonly acceptable significance level, with $\mathrm{F}=4.13$, df $=1$, $25, p<.053$. Finally, irrespective of type of questionnaire, the main effect due to menstrual cycle 


\section{TABLE 1}

LAST CYCLE MEANS OF DAILY AND REMEMBERED SEXUAL AROUSAL FOR 26 WOMEN NOT TAKING ORAL CONTRACEPTIVES, F-VALUES AND SIGNIFICANCE LEVELS

$\begin{array}{lcccc} & \begin{array}{c}\text { Daily } \\ \text { Reports }\end{array} & \begin{array}{c}\text { Remembered } \\ \text { Reports }\end{array} & \begin{array}{c}\text { F-Values* } \\ \text { TxM=6.58 }\end{array} & \begin{array}{c}\text { Significance } \\ \text { Levels }\end{array} \\ \begin{array}{c}\text { Premenstrual Days } \\ (-5 \text { through }-1)\end{array} & 1.99 & 1.83 & \mathrm{M}=3.88 & \mathrm{P}<.003 \\ \begin{array}{c}\text { Menstrual Days } \\ (0 \text { through }+4)\end{array} & 1.90 & 2.04 & \mathrm{~T}=4.13 & \mathrm{P}<.027 \\ \begin{array}{c}\text { Luteal Days } \\ (-13 \text { through }-7)\end{array} & 1.88 & 2.63 & & \end{array}$

* TxM is the interaction effect between the type of questionnaire and menstrual cycle phase, with degrees of freedom df $=2,50$.

$\mathrm{T}$ is the main effect due to type of questionnaire, with $\mathrm{df}=1,25 . \mathrm{M}$ is the main effect due to menstrual cycle phase, with $\mathrm{df}=2,50$.

TABLE 2

LAST CYCLE MEANS OF DAILY AND REMEMBERED SEXUAL AROUSAL FOR 20 WOMEN TAKING COMBINATION LOW PROGESTIN ORAL CONTRACEPTIVES

\begin{tabular}{|c|c|c|c|c|}
\hline & $\begin{array}{l}\text { Daily } \\
\text { Reports }\end{array}$ & $\begin{array}{l}\text { Remembered } \\
\text { Reports }\end{array}$ & F-Values* & $\begin{array}{c}\text { Significance } \\
\text { Levels }\end{array}$ \\
\hline $\begin{array}{l}\text { Premenstrual Days } \\
(-5 \text { through }-1)\end{array}$ & 2.28 & 2.76 & $\mathrm{TxM}=.29$ & $P<.8$ \\
\hline $\begin{array}{l}\text { Menstrual Days } \\
(0 \text { through }+4)\end{array}$ & 2.34 & 2.70 & $M=1.15$ & $\mathrm{P}<.3$ \\
\hline $\begin{array}{l}\text { Luteal Days } \\
\quad(-13 \text { through }-7)\end{array}$ & 2.44 & 3.05 & $\mathrm{~T}=4.23$ & $\mathrm{P}<.054$ \\
\hline
\end{tabular}

* $T \times M$ is the interaction effect between the type of questionnaire and menstrual cycle phase, with degrees of freedom df $=2,38$.

$\mathrm{T}$ is the main effect due to type of questionnaire, with $\mathrm{df}=1,19 . \mathrm{M}$ is the main effect due to menstrual cycle phase, with $\mathrm{df}=2,38$.

phase was significant, $\mathrm{F}=3.88, \mathrm{df}=2,50, p<$ .03. However, it is the interaction effect that sheds light on the fact that self-report of sexual arousal was dependent both on the phase of the cycle and on the type of questionnaire.

Examination of the composite daily self-reports of sexual arousal for women not taking oral contraceptives (Figure 1) indicates that it would have been more desirable to have defined the three phases of the menstrual cycle for the "aware" condition as follows: days -2 and -1 as premenstrual, the first four days of flow as menstruating and days-11 through -3 as luteal. This procedure would have resulted in increased cyclical variability in the analysis of variance shown in Table 1. However, it was impossible to make such a decision prior to the study.

Table 2 shows results of an equivalent analysis for women taking oral contraceptives. Although highest sexual arousal was reported on the remembered questionnaire during the luteal days, cyclical varia- tion in sexual arousal was not significant, $\mathrm{F}=1.15$, $\mathrm{df}=2,38, p<0.3$. The interaction effect between type of questionnaire and menstrual cycle phase was also not significant, $\mathrm{F}=29$, $\mathrm{df}=2,38, p<0.8$. However, irrespective of phase, sexual arousal as reported on the remembered questionnaire was higher than that reported on the daily questionnaire. This difference barely missed the commonly acceptable significance level with $\mathrm{F}=4.23$, $\mathrm{df}=1,19, p<.054$.

Finally, daily self-reports of sexual arousal for 16 males were averaged over the duration of the study.* This average was 3.16. The equivalent average for women not taking oral contraceptives was 2.35 and for women taking oral contraceptives was 2.63. Analysis of variance of these three

*Factor analysis indicated that for men the sexual arousal factor included the items friendly and cooperative. Since these two items did not appear in the sexual arousal factor for women who were taking or not taking oral contraceptives, they were excluded in the computation of the men's average. 
means yielded a significant difference $(\mathrm{F}=4.41$, df $=2,59, p<.02)$. Individual comparisons between the means showed that only the difference between the men and the women not taking oral contraceptives was significant (Tukey's individual comparisons method; $\mathrm{t}=2.96, \mathrm{df}=58, p<.05)$.

\section{DISCUSSION}

The relationships obtained in this study indicate that self-reports of sexual arousal by women not taking oral contraceptives were congruent with a hormonal basis for such arousal when the women were unaware that the menstrual cycle was a salient part of the study. Although progesterone is low during menstruation, the low in sexual arousal during the early days of flow could be partly due to menstrual discomfort.

The peaks and lows of sexual arousal which appear in Figure 1 for women not taking oral contraceptives are in agreement with those reported by Masters and Johnson ${ }^{18}$ and Kaplan. ${ }^{10}$ Furthermore, the premenstrual peak as well as the one appearing near the time of ovulation (i.e., day -13) are congruent with reported increases of orgasm. ${ }^{5}$ However, the peak which appears near the time of ovulation and the low during the first four menstruating days are not in agreement with results reported by Hite. ${ }^{11}$ In her study 56 percent of women reported highest sexual arousal during menstruation and only 11 percent around ovulation. Since the women in her investigation were aware that sexual arousal was being studied as a function of the menstrual cycle, one can only speculate that perhaps they represented a group of women with their own cultural expectations. It is also possible that their menstruating peak referred only to late menstrual days. It is interesting to note that some studies show low coital rates around ovulation. ${ }^{7}$ Rather than associating such results with fear of pregnancy it has been suggested that human sexuality has become less dependent on hormonal control. ${ }^{19}$

The composite daily reports also showed that on the average, over the whole duration of the study, women taking oral contraceptives reported higher levels of sexual arousal compared to women not taking oral contraceptives. This result is not congruent with that of Udry and Morris, ${ }^{6}$ who reported no increase in orgasm for women taking oral contraceptives. Grant and Pryse-Davis ${ }^{20}$ reported that it is high progestin oral contraceptives that lower libido in some women. In our study the oral contraceptives were low in progestin concentrations. It is possible that women who elect to take oral contraceptives are more sexually active/ aroused, and these pills do not inhibit their libido. Finally, the low in sexual arousal on days -6 and 5 for these women was not predicted and remains unexplained at present.

Since not a single subject was suspicious about the true nature of the study, the present results suggest that the self-reports obtained in the "unaware" condition are less biased by cultural expectations about the menstrual cycle. This is further corroborated by the comparison of the questionnaires for the "aware" and "unaware" conditions; women not taking oral contraceptives remembered highest sexual arousal during the luteal phase and lowest premenstrually. Although results for women taking oral contraceptives were not significant, they remembered highest sexual arousal in the luteal and lowest in the menstruating phase. These results are congruent with those reported in the literature, ${ }^{14,16}$ that is, women remember negative affect as occurring premenstrually/menstrually and positive affect in the luteal phase. It should be noted that there is an alternative hypothesis to explain the differences between self-reports in the "aware" and the "unaware" conditions. It is possible that such differences are due to the use of daily versus retrospective questionnaires rather than due to different awareness conditions. To demonstrate that awareness distorts assessment of arousal, a control group is needed in which daily self-reports of "aware" women are obtained. This issue can be settled only by further research.

In conclusion, the results of this study suggest that some of the controversy surrounding female sexual arousal across the menstrual cycle may be due to the variety of ways self-reports have been elicited. Self-report measures of sexual arousal must take into account the awareness of women regarding the purpose of the self-report. When the menstrual cycle was made a salient part of the study, that is, in the "aware" condition, women responded with cultural expectations about the menstrual cycle. However, in the "unaware" condition self-reports by women not taking oral contraceptives followed a pattern congruent with a hormonal basis for sexual arousal. One must therefore question the suggestion that there is no cyclical variability in female sexual arousal or that any cy- 
clicity is simply due to women's misattribution. The present results indicate that "awareness" has an effect on self-reports - a result which perhaps should not be surprising.

\section{INDEX TERMS}

sexuality, female sexuality, menstrual cycle, sexuality and menstrual cycle, oral contraceptives and sexual arousal, sexual arousal.

\section{REFERENCES}

1. Greenblatt, R. B.. E. C. Jungck, and H. Blum. "Endocrinology of Sexual Behavior," Med. Aspects Hum. Sexuality, Vol. 6, 1972, pp. 110-131.

2. Williams, R. H. Textbook of Endocrinology. W. B. Saunders, Philadelphia, 1974.

3. Aedo, A. R., M. Nunez, B. M. Landgren, S. Z. Cekan, and E. Diczfalusy. "Studies on the Pattern of Circulating Steroids in the Normal Menstrual Cycle," Acta Endocrinol., Vol. 84, 1977, pp. 320-332.

4. Guerrero, T., P. F. Brenner, Z. Cekan, B. M. Landgren, K. Hagenfeldt, and E. Diczfalusy. "Studies on the Pattern of Circulating Steroids in the Normal Menstrual Cycle," Acta Endocrinol., Vol. 81, 1976, pp. 133-149.

5. Udry, J. R., and N. M. Morris. "Distribution of Coitus in the Menstrual Cycle," Nature, Vol. 220, 1968, pp. 593-596.

6. "Effects of Contraceptive Pills on the Distribution of Sexual Activity in the Menstrual Cycle," Nature, Vol. 227, 1970, pp. 502-503.

7. James, W. H. "The Distribution of Coitus within the Human Intermenstruum," Biosoc. Sci., Vol. 3, 1971, pp. 159-171.

8. McCullough, R. C. "Rhythms of Sexual Desire and Sexual Activity in the Human Female," unpublished doctoral dissertation, University of Oregon, 1973.
9. O'Connor, J. F., E. M. Shelley, and L. O. Stern. "Behavioral Rhythms Related to the Menstrual Cycle," Biorhythms and Human Reproduction. M. Ferin, et al., eds. Wiley \& Sons, New York, 1974.

10. Kaplan, H. S. The New Sex Therapy. Brunner/Mazel, New York, 1974.

11. Hite, S. The Hite Report. Macmillan Publishing Co., New York, 1977.

12. Spitz, C. J., A. R. Gold, and D. B. Adams. "Cognitive and Hormonal Factors Affecting Coital Frequency," Arch. Sexual Behav., Vol. 4, 1975, pp. 249-263.

13. Ruble, D. N. "Premenstrual Symptoms: A Reinterpretation," Science, Vol. 197, 1977, pp. 291-292.

14. Parlee, M. B. "The Premenstrual Syndrome," Psychol. Bull., Vol. 80, 1973, pp. 454-456.

15. "Stereotypic Beliefs about Menstruation: A Methodological Note on the Moos Menstrual Distress Questionnaire and Some New Data," Psychosom. Med., Vol. 36, 1974, pp. 229-240.

16. Englander-Golden, P., M. Whitmore, and R. Dienstbier. "Effects of Saliency of Menstruation on Self-report Measures of Moods and Behaviors," Motivation and Emotion, Vol. 2, No. 1, 1978, pp. 75-86.

17. Golub, S. "The Magnitude of Premenstrual Anxiety and Depression," Psychosom. Med., Vol. 38, No. 1, 1976, pp. 4-12.

18. Masters, W. H., and V. E. Johnson. Human Sexual Response. Little Brown, Boston, 1966.

19. Wiggins, J. S., K. E. Renner, G. L. Clore, and R. J. Rose. The Psychology of Personality. Addison-Wesley, Reading, 1971.

20. Grant, E. C. G., and J. Pryse-Davis. "Effect of Oral Contraceptives on Depressive Mood Changes and on Endometrial Monoamine Oxidase and Phosphates," Br. Med. J., Vol. 3, 1968, pp. 777-780. 